\title{
Novel Energy-Saving Steer-by-Wire System for Articulated Steering Vehicles: A Compact Wheel Loader Case Study
}

\author{
Naseem Daher, Chuang Wang, and Monika Ivantysynova \\ School of Mechanical Engineering, Purdue University, West Lafayette, Indiana, USA \\ Email: ndaher@purdue.edu, wang1310@purdue.edu, mivantys@ purdue.edu
}

\begin{abstract}
Improving energy efficiency remains a priority in the industrial and academic communities given the ever increasing demand on fossil fuels and their skyrocketing prices. Pump displacement controlled (DC) actuation is an energy efficient alternative to traditional valve controlled actuation. The technology has shown significant fuel savings on mobile machinery when applied to the working hydraulics (implement) functions of such machines. However, DC actuation has never been investigated for use on mobile machinery chassis systems, namely power steering. In this paper and for the first time, a novel closed-circuit pump DC system architecture is devised to perform the power steering system function of a compact wheel loader. A dynamic model of the new system was generated to corroborate concept feasibility, perform system sizing and analysis, and predict performance during standard steering maneuvers. Simulation results showed that a DC power steering system is a feasible, promising, and challenging alternative, which upon further research and development will be brought to life and tested on a prototype machine.
\end{abstract}

Keywords: displacement control, articulated steering, power steering, dynamic modeling

\section{Introduction}

Demand for power steering originated from the need for providing assistance to operators in achieving their heading directions, especially as transportation vehicles grew in size and mass. While the main requirements of primitive systems were simply adequate assistance levels and acceptable controllability, today's requirements are more stringent. Given the increased awareness and attention paid to energy efficiency, productivity, and safety, researching alternative technologies is underway. Present-day power steering systems include hydraulic, electric, and electro-hydraulic architectures, which vary based on their energy source, energy transmission, and energy management schemes. Hydraulic power steering is plagued with poor energy efficiency mainly due to throttling losses associated with hydraulic control valves. Electric power steering systems offer better energy efficiency with on-demand power supply and result in improved packaging constraints, but suffer from power limitations at larger vehicle segments. State-ofthe-art electrohydraulic steering systems take advantage of the high power density and efficiency of fluid power, but use electronically controlled valves that still suffer from energy inefficiency.

This paper introduces a novel electrohydraulic steer-by-wire steering system and uses a compact wheel loader as a case study. The paper details the high-fidelity co-simulation plant model consisting of a coupled hydraulics and dynamics modules. The new system utilizes a proven energy-saving technology, Displacement Control (DC) developed by
Rahmfeld and Ivantysynova (1998), which eliminates hydraulic control valves throttling losses by directly controlling the pump displacement instead.

\section{Displacement Control Power Steering}

Displacement Control (DC) steering can be classified under electro-hydrostatic power steering, where the steering wheel torque / angle and vehicle speed are sensed and fed back to a controller that adjusts the displacement of a variable displacement pump as opposed to controlling a proportional valve. Figure 1 is provided for identification of components in the proposed circuitry. The actuator (8) velocity is controlled by adjusting the pump (2) speed, displacement, or both. The pump input/output ports are connected to the piston/rod sides of the actuator. The differential fluid flow between the actuator's uneven sides is overcome by means of pilot-operated check valves (6), which keep the low pressure side of the actuator connected to a low pressure source that can either provide or absorb flow to balance the unequal cylinder flow. The low pressure source has its own fixed displacement charge pump (4), driven by the same prime mover (1), providing continuous flow to the cylinder's low pressure side and the pump control system. The low pressure level setting is adjusted via a pressure relief valve (5). An accumulator (not shown) could be used in order to provide high flow rate spikes when sudden high speed cylinder movements are incurred, if the charge pump flow is not sufficient. The system is protected from overpressurization by means of pressure relief valves (7) installed on both sides of the actuator. 


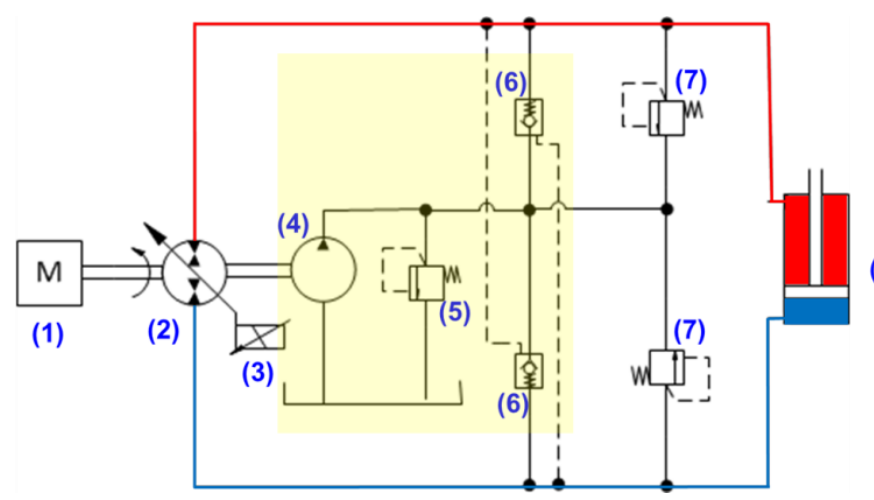

Figure 1: DC Steering Hydraulic Schematic

The pump control system (3), which is detailed in fig. 2, uses a single stage proportional control valve that meters flow to a double rod actuator connected to the pump swash plate. The actuator linear displacement determines the angular position of the swash plate, and therefore the instantaneous pump displacement volume per revolution.



Figure 2: Pump Swash Plate Control System

\section{System Modeling}

In this section, a detailed dynamic model of the DC steering system plant is described. The system level model is composed of two main building blocks: a hydraulics module and a mechanics one. Figure 3 shows a top-level block diagram of the system model structure and setup. The hydraulics module delivers the required flow rates to induce motion in the linear actuators, which translates into vehicle artiuclation. The pressure levels in the actuator sides are determined by the load computed within the mechanics module mainly due to the opposing loads generated at the ground-tire interface.



Figure 3: Block Diagram of DC Steering System Model

\subsection{Hydraulics Subsystem Model}

The hydraulics module includes a variable displacement pump / motor unit modeled with its associated volumetric and torque losses, transmission line losses, a pump control system, a low pressure source system, and a pressure-flow model to determine pressure build-up inside the actuator.

\subsubsection{Variable Displacement Pump/Motor Model}

The variable displacement axial piston machine is modeled with careful consideration to volumetric and torque losses incurred throughout the entire pump operating range. First, the derived (actual) pump displacement volume is determined using the Toet method. Second, steady-state measurements are recorded at various speeds, displacements, and pressures at constant inlet temperature. The measured data is then fitted to a $3^{\text {rd }}$ degree polynomial to generate the proper loss coefficients as functions of operating conditions. Following are the governing equations that were used to generate the pump model, provided in pumping mode operation.

$$
Q_{e}=\beta V_{d} n-Q_{s}
$$

where $Q_{e}$ is the effective pump flow rate, $\beta$ is the normalized pump swash plate angle, $\mathrm{V}_{\mathrm{d}}$ is the derived pump displacement volume, $\mathrm{n}$ is the pump speed, and $\mathrm{Q}_{\mathrm{s}}$ is the volumetric loss flow rate given by eq. (2).

$$
Q_{s}\left(V_{d}, n, \Delta p\right)_{T=\text { const. }}=\sum_{i_{1}=0}^{I_{1}} \sum_{i_{2}=0}^{I_{2}} \sum_{i_{3}=0}^{I_{3}} K_{Q}\left(i_{1}, i_{2}, i_{3}\right) \cdot V_{d}^{i_{1}} \cdot n^{i_{2}} \cdot \Delta p^{i_{3}}
$$

The pump effective torque, $\mathrm{T}_{\mathrm{e}}$, is given by eq. (3):

$$
T_{e}=\beta V_{d} \Delta p+T_{s}
$$

where $\Delta \mathrm{p}$ is the pressure differential across the pump ports, and $\mathrm{T}_{\mathrm{s}}$ is the torque loss given by eq. (4).

$T_{s}\left(V_{d}, n, \Delta p\right)_{T=c s t}=\sum_{i_{1}=0}^{I_{1}} \sum_{i_{2}=0}^{I_{2}} \sum_{i_{3}=0}^{I_{3}} K_{T}\left(i_{1}, i_{2}, i_{3}\right) \cdot V_{d}^{i_{1}} \cdot n^{i_{2}} \cdot \Delta p^{i_{3}}$

The derived pump displacement volume obtained via the Toet method is given in eq. (5).

$$
V_{d}=\frac{1}{n} . \frac{\sum_{j=1}^{k} Q_{e j} \cdot \sum_{j=1}^{k} \Delta p_{j}^{2}-\sum_{j=1}^{k} \Delta p_{j} \cdot \sum_{j=1}^{k} \Delta p_{j} \cdot Q_{e j}}{k \cdot \sum_{j=1}^{k} \Delta p_{j}^{2}-\left(\sum_{j=1}^{k} \Delta p_{j}\right)^{2}}
$$

\subsubsection{Pressure-Flow Equations}

The pressure build-up inside the actuator chambers is determined from the conservation of mass principle, which leads to the pressure being a function of the sum of flow 
rates entering / leaving the chambers multiplied by the reciprocal of the control volumes hydraulic capacitance. In the following equations, the zero-position is assumed to be at mid-stroke, and the actuator displacement / velocity are positive during the compression stroke (fig. 4).

$$
p_{A}=\frac{1}{C_{H A}} \int\left(Q_{A}+A_{A} \cdot \dot{x}-Q_{L i}-Q_{r}\right) d t
$$

where $\mathrm{p}_{\mathrm{A}}$ is the piston (A) side pressure, $\mathrm{C}_{\mathrm{HA}}$ is control volume $\mathrm{A}$ hydraulic capacitance, $\mathrm{Q}_{\mathrm{A}}$ is the net flow entering the piston chamber, $A_{A}$ is the piston side area, $\dot{x}$ is the actuator velocity, $\mathrm{Q}_{\mathrm{Li}}$ is the internal leakage flow across the actuator chambers, and $\mathrm{Q}_{\mathrm{r}}$ is the relief valve flow rate.

$$
C_{H A}=\frac{1}{K}\left\{\left(\frac{H}{2}-x\right) A_{A}+V_{\text {dead }}+V_{L A}\right\}
$$

Where $\mathrm{K}$ is the fluid bulk modulus, $\mathrm{H}$ is the total actuator stroke, $\mathrm{x}$ is the actuator position, $\mathrm{V}_{\text {dead }}$ is the dead volume inside the actuator, and $\mathrm{V}_{\mathrm{LA}}$ is the transmission line $\mathrm{A}$ volume.

Similarly, the pressure on side B (rod) is determined via eq. (8) and eq. (9).

$$
\begin{gathered}
p_{B}=\frac{1}{C_{H B}} \int\left(-Q_{B}-A_{B} \cdot \dot{x}+Q_{L i}-Q_{r}\right) d t \\
C_{H B}=\frac{1}{K}\left\{\left(\frac{H}{2}+x\right) A_{B}+V_{\text {dead }}+V_{L B}\right\}
\end{gathered}
$$

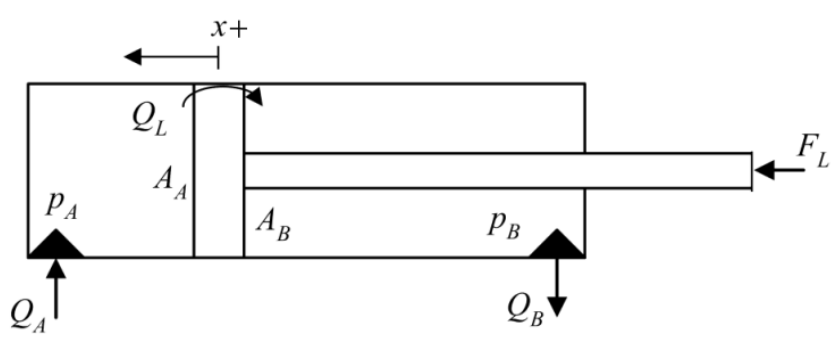

Figure 4: Actuator Pressure-Flow Diagram

\subsubsection{Actuator Friction Model}

The sliding friction behavior between the actuator's rod and cylinder housing is modeled based on the Stribeck curve regime, which accounts for static friction, coulomb friction, and viscous friction effects.

$$
F_{R}(\dot{x})=d_{v} \dot{x}+\operatorname{sign}(\dot{x})\left(F_{C}+F_{H} e^{\frac{-|\dot{x}|}{\tau_{H}}}\right)
$$

where $F_{R}$ is the resultant friction force, $d_{v}$ is the viscous friction coefficient, $F_{C}$ is the Coulomb friction force, $F_{H}$ is the static friction force, and $\tau_{\mathrm{H}}$ is the static friction force constant. A sample plot of the actuator friction force is shown in fig. 5 .

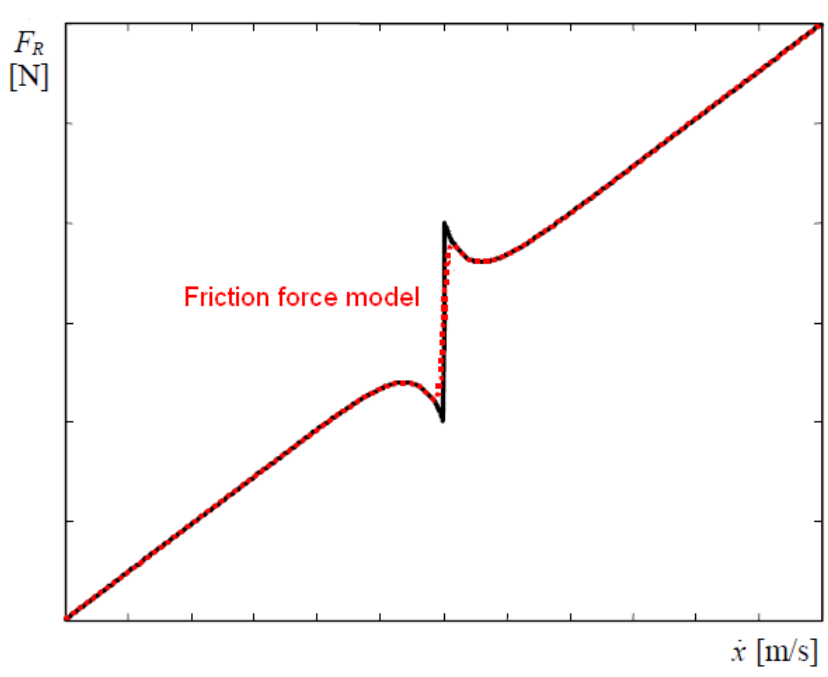

Figure 5: Actuator Stribeck Friction Curve

\subsubsection{Transmission Line Losses}

Transmission line losses are derived from the Navier-Stokes equations by balancing the pressure forces against the viscous forces. Given that the lines configuration and fluid viscosity are virtually constant, the pressure drop in the transmission lines, $\Delta \mathrm{p}_{\mathrm{L}}$, could be determined by multiplying the effective flow rate by a constant gain per eq. (11).

$$
\Delta p_{L}=\frac{8 \mu l_{L} v}{R_{L}^{2}}=\left[\frac{8 \mu l_{L}}{A_{L} \cdot R_{L}^{2}}\right] \cdot Q_{e}
$$

where $\mu$ is the fluid dynamic viscosity, $v$ is the fluid kinematic viscosity, and $\mathrm{l}_{\mathrm{L}}, \mathrm{R}_{\mathrm{L}}$, and $\mathrm{A}_{\mathrm{L}}$ are the transmission line length, radius, and area respectively.

\subsubsection{Low Pressure System}

The low pressure system consists of a fixed positive displacement charge pump, two pressure relief valves, and two pilot-operated check valves (POCV) shown in fig. 6 .



Figure 6: Pilot-Operated Check Valve

The POCV is modeled using a force balance on the pilot spool, which determines both its displacement, $y_{c}$, as well as the mode of operation i.e. normal flow versus reverse flow.

Normal Flow Direction:

$$
y_{c}=\frac{1}{k_{0}}\left[A_{c}\left(p_{L P}-p_{2}\right)-F_{k 0}\right]
$$

$\underline{\text { Reverse Flow Direction: }}$ 


$$
y_{c}=\frac{1}{k_{0}}\left[A_{s p}\left(p_{1}-p_{L P}\right)+A_{c}\left(p_{L P}-p_{2}\right)-F_{k 0}\right]
$$

The resulting POCV flow is given by eq. (14).

$$
\begin{gathered}
Q_{c}=\alpha_{D} \sqrt{\pi A_{c}} 2 y_{c} \operatorname{sign}(\Delta p) \sqrt{\frac{2}{\rho}|\Delta p|} \\
\Delta p=p_{1 / 2}-p_{L P}
\end{gathered}
$$

where $A_{c}$ is the cone orifice area, $p_{L P}$ is the pressurized low pressure, $\mathrm{p}_{1}$ is the pilot pressure, $\mathrm{p}_{2}$ is the cylinder / outlet pressure, $F_{K 0}$ is the spring pre-load force, $\mathrm{k}_{0}$ is the spring rate, $A_{s p}$ is the spool area, and $\alpha_{D}$ is the discharge coefficient.

\subsubsection{Pump Control System}

The dynamics of the pump control system responsible for adjusting the swash plate angle are dominated by the servovalve dynamics, which are modeled as a linear second order transfer function from the commanded input voltage signal, $\mathrm{u}_{\mathrm{SV}}$, to the output spool position, $\mathrm{y}_{\mathrm{sV}}$, per eq. (16).

$$
\frac{Y_{S V}(s)}{U_{S V}(s)}=\frac{\omega_{S V}^{2}}{s^{2}+2 \zeta_{S V} \omega_{S V} s+\omega_{S V}^{2}}
$$

where $\omega_{\mathrm{SV}}$ is the servovalve natural frequency and $\zeta_{\mathrm{Sv}}$ is the valve's damping ratio.

\subsection{Mechanics Module}

Two separate mechanics modules were generated to allow for performing simulations of two types of common wheel loader maneuvers. The first model is a 1-DOF model where the loader articulates while stationary, simulating a truck loading cycle where the load is transferred from one side to the other. The second model is a 3-DOF model where the loader articulates as it travels, simulating transferring a load at a work site.

\subsubsection{1-DOF Dynamic Model}

The wheel loader was modeled as two sub-frames connected in the center at the articulation (revolute) joint. For simplicity, the rear sub-frame was fixed to the ground and only the front sub-frame was allowed to rotate, resulting in 1-DOF motion. The linear actuator was modeled as two rigid bodies, rod and cylinder, moving relative to one another along an axial (prismatic) joint. The hydraulic force acts on the rod causing it to translate inside the cylinder, which induces rotational motion of the sub-frame about the articulation (revolute) joint. The rotational motion is a result of the balance of moments about the articulation joint (fig. 7) given in eq. (17).

$$
F_{s t r} * r_{j}-N_{f} \cdot \mu_{t f} \cdot \frac{w b}{2}-\left(d_{A J}+d_{\text {Tire } \_ \text {Lat }}\right) \cdot \omega_{f}=I_{f} \dot{\omega}_{f}
$$

where $F_{\text {str }}$ is the steering force, $r_{j}$ is the normal distance between the articulation joint and the steering actuator force line of action, $\mathrm{N}_{\mathrm{f}}$ is the front axle normal load, wb is the vehicle wheelbase, $\mu_{\mathrm{tf}}$ is the friction coefficient between the tire and the ground, $\mathrm{d}_{\mathrm{AJ}}$ is the articulation joint damping coefficient, $\mathrm{d}_{\text {Tire_Lat }}$ is the tires lateral damping coefficient, $\omega_{\mathrm{f}}$ is the front sub-frame articulation angle rate, and $I_{f}$ is the front sub-frame moment of inertia.

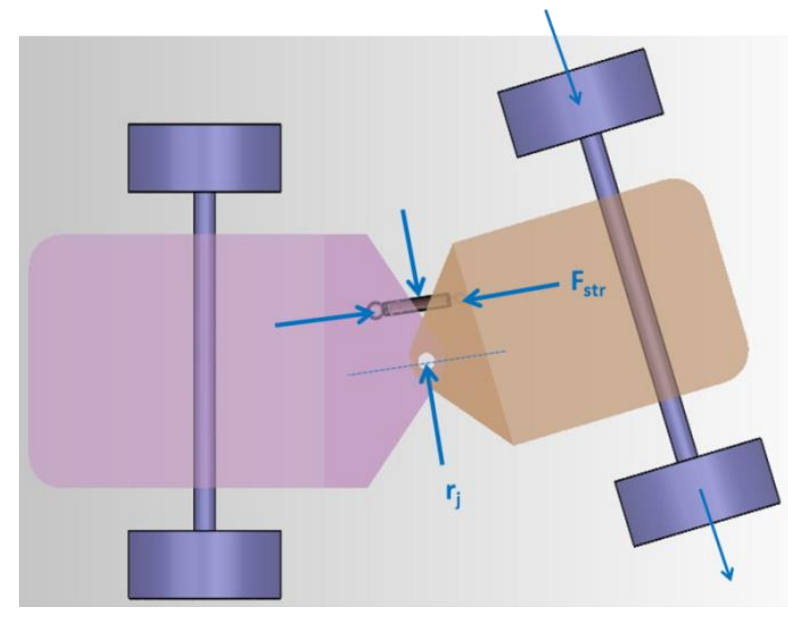

Figure 7: 1-DOF Dynamic Model

\subsubsection{3-DOF Dynamic Model}

The 1-DOF model only allows for simulating static steering maneuvers. In order to simulate a moving vehicle, a multiDOF model is then required. However, making changes to the steering system of any moving vehicle requires a deep understanding of the vehicle dynamics aspect. The mechanics module primarily consists of a 3-DOF vehicle dynamics model based on the Lagrangian equation. The Lagrangian approach was adopted due to the complexity of forces and constraints associated with articulated vehicles, where the Newtonian approach is strenuous to apply given the vectorial nature and continuous variation of the forces and accelerations at hand.

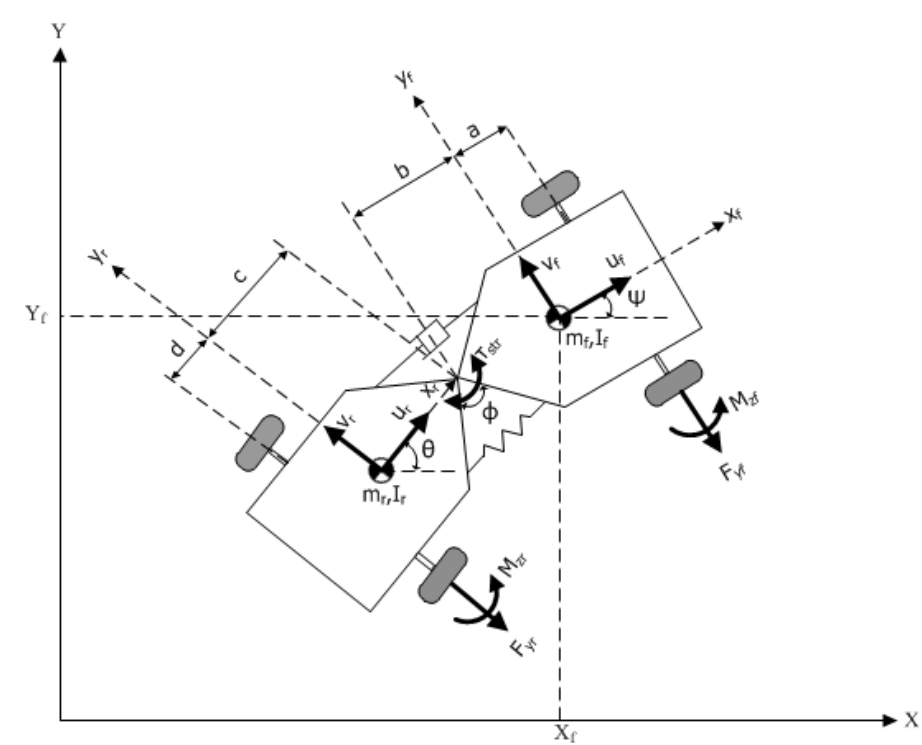

Figure 8: Articulated Vehicle Dynamics

The standard form of the Lagrange equation is given in eq. (18) below: 


$$
\frac{d}{d t}\left(\frac{\partial L}{\partial \dot{q}_{i}}\right)-\frac{\partial L}{\partial q_{i}}+\frac{\partial D}{\partial \dot{q}_{i}}=Q_{i}
$$

where $\mathrm{L}$ is the Lagrangian function (defined as kinetic energy, $\mathrm{T}$, minus potential energy, $\mathrm{V}$ ), $\mathrm{q}$ is the set of generalized coordinates, $\mathrm{D}$ is the dissipative function, and $\mathrm{Q}_{\mathrm{i}}$ is the set of generalized forces and moments. The kinetic energy includes the translational and rotational motions of two constrained sub-frames as shown in eq. (19). The potential energy and dissipative function are functions of the (equivalent) torsional spring and damping constants, and the articulation angle / rate as shown in eq. (20) and eq. (22).

$$
\begin{gathered}
T=\frac{1}{2} m_{f}\left(\dot{X}_{f}^{2}+Y_{f}^{2}\right)+\frac{1}{2} I_{f} \dot{\psi}^{2}+\ldots \\
\frac{1}{2} m_{r}\left(\dot{X_{r}^{2}}+\dot{Y}_{r}^{2}\right)+\frac{1}{2} I_{r} \dot{\theta}^{2} \\
V=\frac{1}{2} K_{a j}(\psi-\theta)^{2} \\
L=T-V \\
D=\frac{1}{2} C_{a j}(\dot{\psi}-\dot{\theta})^{2}
\end{gathered}
$$

Given the constraint imposed by the articulation joint, the rear sub-frame motion can be expressed in terms of the front sub-frame motion, yielding the modified kinetic energy expression given by eq. (23).

$$
\begin{aligned}
& T=\frac{1}{2} m_{f}\left(\dot{X}_{f}^{2}+Y_{f}^{2}\right)+\frac{1}{2} I_{f} \dot{\psi}^{2}+\ldots \\
& \frac{1}{2} m_{r}\left[\left(\dot{X}_{f}+b \sin \psi \dot{\psi}+c \sin \theta \dot{\theta}\right)^{2}+\ldots\right. \\
& \left.\left(\dot{Y}_{f}-b \cos \psi \dot{\psi}-c \cos \theta \dot{\theta}\right)\right]^{2}+\frac{1}{2} I_{r} \dot{\theta}^{2}
\end{aligned}
$$

The originally selected set of generalized coordinates, q, consisted of the global $\mathrm{X}$ and $\mathrm{Y}$ coordinates, and the angles, $\psi$ and $\theta$, which the front and rear sub-frames make relative to the global $\mathrm{X}$ abscissa, respectively. However, to allow for performing maneuvers with large deviations from the global axes such as steady-state cornering, and to reduce the order of the system, a coordinate transformation to the local front sub-frame longitudinal and lateral velocities, $u_{f}$ and $v_{f}$ respectively, is necessary per eq. (24) and eq. (25).

$$
\begin{aligned}
& u_{f}=\dot{X}_{f} \cos \psi+\dot{Y}_{f} \sin \psi \\
& v_{f}=-\dot{X}_{f} \sin \psi+\dot{Y}_{f} \cos \psi
\end{aligned}
$$

As a result the Lagrangian equations of the $\mathrm{X}$ and $\mathrm{Y}$ coordinates are replaced with those of $u_{f}$ and $v_{f}$ respectively.

$$
\begin{aligned}
& \frac{d}{d t} \frac{\partial T}{\partial u_{f}}-\frac{\partial T}{\partial v_{f}} \dot{\psi}=Q_{u_{f}} \\
& \frac{d}{d t} \frac{\partial T}{\partial v_{f}}+\frac{\partial T}{\partial u_{f}} \dot{\psi}=Q_{v_{f}}
\end{aligned}
$$

Another substitution that simplifies the system of equations as well as allows for explicitly stating the articulation angle, $\phi$ (a desired state variable), is to apply eq. (28).

$$
\phi=\psi-\theta
$$

Consequently, the following set of coordinates was selected:

$$
\mathbf{q}(t)=\left(u_{f}, v_{f}, \dot{\psi}, \dot{\phi}\right)^{T}
$$

where $\dot{\psi}$ is the front yaw angle rate, and $\dot{\phi}$ is the articulation angle rate.

Next, the rear sub-frame local velocities are expressed in terms of the front sub-frame local velocities assuming small articulation angle approximation.

$$
\begin{gathered}
u_{r}=u_{f}-v_{f} \phi+b \phi \dot{\psi} \\
v_{r}=u_{f} \phi+v_{f}-(b+c) \dot{\psi}+c \dot{\phi}
\end{gathered}
$$

At last, the kinetic energy is now expressed in terms of the desired generalized coordinates, $\mathrm{u}_{\mathrm{f}}, \mathrm{v}_{\mathrm{f}}, \psi$, and $\phi$ as shown in eq. (32).

$$
\begin{aligned}
T= & \frac{1}{2} m_{f}\left(u_{f}^{2}+v_{f}^{2}\right)+\frac{1}{2} I_{f} \dot{\psi}^{2}+\frac{1}{2} m_{r}\left[u_{f}^{2}+v_{f}^{2} \phi^{2} \ldots\right. \\
& +b^{2} \phi^{2} \dot{\psi}^{2}-2 u_{f} v_{f} \phi+2 b u_{f} \dot{\phi} \dot{\psi}-2 b v_{f} \phi^{2} \dot{\psi}+u_{f}^{2} \phi^{2} \ldots \\
& +v_{f}^{2}+(b+c)^{2} \dot{\psi}^{2}+2 u_{f} v_{f} \phi-2 u_{f} \phi(b+c) \dot{\psi} \ldots \\
& -2 v_{f}(b+c) \dot{\psi}+c^{2} \dot{\phi}^{2}+2 u_{f} c \phi \dot{\phi}+2 v_{f} c \dot{\phi} \ldots \\
& -2 c(b+c) \dot{\phi} \dot{\psi}]+\frac{1}{2} I_{r} \dot{\psi}^{2}-I_{r} \dot{\psi} \dot{\phi}+\frac{1}{2} I_{r} \dot{\phi}^{2}
\end{aligned}
$$

Using the virtual work principle, the right hand sides of the Lagrangian equations are resolved. Referring to fig. 8, the following virtual work equation is arrived at.

$$
\begin{aligned}
\delta W= & \delta_{y_{f}}\left(F_{y_{f}}+F_{y_{r}}\right)+\ldots \\
& \delta \psi\left[a F_{y_{f}}-(b+c+d) F_{y r}+M_{z f}+M_{z r}\right]+\ldots \\
& \delta \phi\left[(c+d) F_{y r}-M_{z r}\right]
\end{aligned}
$$

For determining the tire lateral forces, it is first necessary to determine the tire lateral slip angles. The tire lateral slip angle is defined as the angle between the actual traveling direction of the tire and the direction of the tire centerline. Using small angle approximation, the average slip angles of the front and rear tires are given by eq. (34) and eq. (35). 


$$
\begin{gathered}
\alpha_{f}=\frac{v_{f}+a \dot{\psi}}{u_{f}} \\
\alpha_{r}=\frac{v_{f}-(b+c+d) \dot{\psi}+(c+d) \dot{\phi}}{u_{f}}+\phi
\end{gathered}
$$

For this paper, the linear tire model is used given its simplicity, linear property, and applicability for the maneuvers under consideration relative to speed, articulation angle, and such. The linear tire model is given by eq. (36) through eq. (39).

$$
\begin{gathered}
F_{y_{f}}=-N_{f} C_{\alpha_{f}} \alpha_{f} \\
F_{y_{r}}=-N_{r} C_{\alpha_{r}} \alpha_{r} \\
M_{z f}=N_{f} C_{M \alpha f} \alpha_{f}=N_{f} C_{M \alpha f}\left(\frac{v_{f}+a \dot{\psi}}{u_{f}}\right) \\
M_{z r}=N_{r} C_{M \alpha r}\left(\frac{v_{f}-(b+c+d) \dot{\psi}+(c+d) \dot{\phi}}{u_{f}}+\phi\right)
\end{gathered}
$$

where $\mathrm{F}_{\mathrm{yf}}$ and $\mathrm{F}_{\mathrm{yr}}$ are the front and rear tire lateral forces respectively, $\mathrm{N}_{\mathrm{f}}$ and $\mathrm{N}_{\mathrm{r}}$ are the front and rear axle vertical loads respectively, and $\mathrm{C}_{\mathrm{af}}$ and $\mathrm{C}_{\mathrm{ar}}$ are the front and rear tires lateral force coefficients respectively. $\mathrm{M}_{\mathrm{zf}}$ and $\mathrm{M}_{\mathrm{zr}}$ are the front and rear tire aligning moments respectively, and $\mathrm{C}_{\mathrm{Maf}}$ and $\mathrm{C}_{\mathrm{Mar}}$ are the front and rear tire aligning moment coefficients respectively. The tire normal loads are determined based on equilibrium analysis of forces and moments leading to the expression of the tire normal forces in terms of the defined vehicle parameters shown in fig. 8 .

$$
\begin{gathered}
N_{f}=\frac{m_{r} g d+m_{f} g(b+c+d)}{a+b+c+d} \\
N_{r}=\frac{m_{f} g a+m_{r} g(a+b+c)}{a+b+c+d}
\end{gathered}
$$

\section{$\underline{\text { EOM for Generalized coordinate }} v_{f}$ :}

The EOM for $\mathrm{v}_{\mathrm{f}}$ is obtained after taking time derivatives, partial derivatives, ignoring nonlinear and second order terms, and substituting the generalized force, $Q_{v f}$, in the Lagrange equation.

$$
\begin{aligned}
& \left(m_{f}+m_{r}\right) \dot{v_{f}}+\left(-b m_{r}-c m_{r}\right) \ddot{\psi}+\left(m_{f}+m_{r}\right) u_{f} \dot{\psi}+\left(c m_{r}\right) \ddot{\phi}= \\
& \left(\frac{-N_{f} C_{\alpha f}-N_{r} C_{\alpha r}}{u_{f}}\right) \cdot v_{f}-\left(\frac{N_{r} C_{\alpha r}(c+d)}{u_{f}}\right) \dot{\phi}-\left(N_{r} C_{\alpha r}\right) \phi \ldots \\
& +\left(\frac{-a N_{f} C_{\alpha f}-(b+c+d) N_{r} C_{\alpha r}}{u_{f}}-\left(m_{f}+m_{r}\right) u_{f}\right) \dot{\psi}
\end{aligned}
$$

The EOM for the remaining two generalized coordinates are obtained in a similar fashion and are listed below in eq. (43) and eq. (44) for completeness.

EOM for Generalized coordinate $\dot{\psi}$

$$
\begin{aligned}
& \dot{v}_{f}\left[-m_{r}(b+c)\right]+\ddot{\psi}\left[I_{f}+I_{r}+m_{r}(b+c)^{2}\right] \\
& +\ddot{\phi}\left(-m_{r} b c-m_{r} c^{2}-I_{r}\right)-\dot{\psi}\left[m_{r}(b+c) u_{f}\right]= \\
& v_{f}\left[\frac{-a N_{f} C_{\alpha f}+(b+c+d) N_{r} C_{\alpha r}+N_{f} C_{M \alpha f}+N_{r} C_{M \alpha r}}{u_{f}}\right] \ldots \\
& +\dot{\psi}\left[\frac{\left(\begin{array}{l}
-a^{2} N_{f} C_{\alpha f}-(b+c+d)^{2} N_{r} C_{\alpha r} \\
+a N_{f} C_{M \alpha f}-(b+c+d) N_{r} C_{M \alpha r}
\end{array}\right)}{u_{f}}+m_{r}(b+c) u_{f}\right] \cdots \\
& +\dot{\phi}\left[\frac{(b+c+d)(c+d) N_{r} C_{\alpha r}+(c+d) N_{r} C_{M \alpha r}}{u_{f}}\right] \ldots \\
& +\phi\left[(b+c+d) N_{r} C_{\alpha r}+N_{r} C_{M \alpha r}\right]
\end{aligned}
$$

EOM for Generalized coordinate $\dot{\phi}$ :

$$
\begin{aligned}
& \dot{v}_{f}\left(m_{r} c\right)+\ddot{\psi}\left(-m_{r} c^{2}-m_{r} b c-I_{r}\right) \\
& +\ddot{\phi}\left(m_{r} c^{2}+I_{r}\right)= \\
& v_{f}\left[\frac{\left.-(c+d) N_{r} C_{\alpha r}-N_{r} C_{M \alpha r}\right]+\ldots}{u_{f}}\right] \\
& \dot{\psi}\left[\frac{(c+d)(b+c+d) N_{r} C_{\alpha r}+N_{r} C_{M \alpha r}(b+c+d)}{u_{f}}\right]+\ldots \\
& \dot{\phi}\left[\frac{-(c+d)^{2} N_{r} C_{\alpha r}-N_{r} C_{M r}(c+d)}{u_{f}}-m_{r} c u_{f} \dot{\phi}-C_{a}\right]+\ldots \\
& \phi\left[-N_{r} C_{\alpha r}-N_{r} C_{M \alpha r}\right]
\end{aligned}
$$

At this point, the equations of motion are expressed in a manner such that the derivatives of the selected generalized coordinates are on the left hand side, whereas the generalized coordinates themselves are on the right hand side of the equations. This format is in accordance with a system of linear first order differential equations. Such formulation lends itself to expressing the system in state space format, which is currently under development for generating a linear model to be used for designing a controller based on modern control theory.

\subsection{MSC Adams Model}

The compact wheel loader under investigation is designated as the baseline test vehicle to be used for model validation, hardware implementation, and controller development. The 
generated models in this paper were developed based on the parameters of the baseline vehicle shown in tab. 1 .

\begin{tabular}{|c|c|c|c|}
\hline Parameter & Description & Value & Unit \\
\hline$m$ & Vehicle Mass & 4100 & $\mathrm{~kg}$ \\
\hline$m_{f}$ & Front Sub-frame Mass & 1640 & $\mathrm{~kg}$ \\
\hline$m_{r}$ & Rear Sub-frame Mass & 2460 & $\mathrm{~kg}$ \\
\hline$\overline{I_{f}}$ & $\begin{array}{l}\text { Front Sub-frame Moment of } \\
\text { Inertia }\end{array}$ & 1500 & $\mathrm{~kg} \cdot \mathrm{m}^{2}$ \\
\hline$\overline{I_{r}}$ & $\begin{array}{l}\text { Rear Sub-frame Moment of } \\
\text { Inertia }\end{array}$ & 2500 & kg.m ${ }^{2}$ \\
\hline$w b$ & Vehicle Wheelbase & 2.12 & $\mathrm{~m}$ \\
\hline$a$ & $\begin{array}{lll}\text { Distance } & \text { Between } & \text { Front } \\
\text { Sub-frame } & \text { CG and } & \text { Front } \\
\text { Axle } & & \\
\end{array}$ & 0 & $\mathrm{~m}$ \\
\hline$b$ & $\begin{array}{l}\text { Distance Between Front CG } \\
\text { and Articulation Joint }\end{array}$ & 1.06 & $\mathrm{~m}$ \\
\hline$c$ & $\begin{array}{l}\text { Distance Between Rear CG } \\
\text { and Articulation Joint }\end{array}$ & 1.06 & $\mathrm{~m}$ \\
\hline$d$ & $\begin{array}{l}\text { Distance Between Rear Sub- } \\
\text { frame CG and Front Axle }\end{array}$ & 0 & $\mathrm{~m}$ \\
\hline$r_{j}$ & $\begin{array}{l}\text { Normal Distance Between } \\
\text { the Articulation Joint and the } \\
\text { Steering Actuator Force Line } \\
\text { of Action }\end{array}$ & 0.2 & $\mathrm{~m}$ \\
\hline
\end{tabular}

Table 1: Baseline Wheel Loader Parameters

A multi-body dynamics model was generated in MSC Adams software for two purposes. First, it allows for performing accurate simulations of dynamic steering maneuvers when coupled with the hydraulic subsystem. Second, it will provide a platform for validating the derived linear model, which will be used for advancing the research forward relative to control algorithms development. The model's topology comprises two rigid bodies connected at the articulation joint via a revolute joint. When no articulation angle input is present i.e. no flow to/from the actuator and ignoring leakage across the actuator sides, the hydraulic fluid inside the steering actuator creates the effect of a (stiff) torsional spring at the joint, whose stiffness, $\mathrm{K}_{\mathrm{aj}}$, is approximated via eq. (45), which results from the pressure-flow equation.

$$
K_{a j}=\frac{K}{V_{t}} A_{A}^{2}\left(1+\alpha^{2}\right) \gamma r_{j}
$$

where $\mathrm{K}$ is the fluid bulk modulus, $\mathrm{V}_{\mathrm{t}}$ is the total volume of fluid under compression including actuator chambers and transmission lines, $\mathrm{A}_{\mathrm{A}}$ is the actuator piston area, $\alpha$ is the area ratio between the actuator sides, $\gamma$ is a linear conversion factor between the steering actuator linear motion and the vehicle rotational motion, and $r_{j}$ is the normal distance between the articulation joint and the steering actuator force line of action. As for damping, the articulation joint friction along with the tires lateral damping play the role of a torsional damper present at the joint. This parameter was estimated based on literature review [1] due to lack of measurements at the present time. The PAC 2002 MagicFormula tire model was selected, which is suitable for the considered maneuvers involving single-lane change and steady-state cornering. Figure 9 shows the generated Adams model that was used during the simulation run.

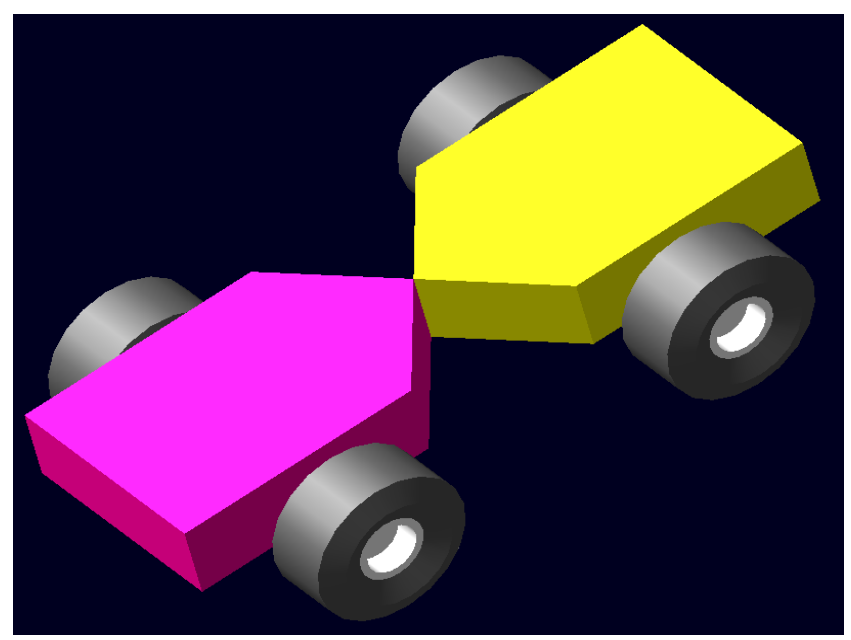

Figure 9: Adams Model of an Articulated Vehicle

\subsection{MATLAB Simulink SimMechanics ${ }^{\mathrm{TM}}$ Model}

A 1-DOF dynamic model was designed in MATLAB Simulink SimMechanics ${ }^{\mathrm{TM}}$ environment. The main purpose of the model is to generate a load that the hydraulic subsystem must overcome to induce articulation while the vehicle performs static maneuvers i.e. zero forward speed.

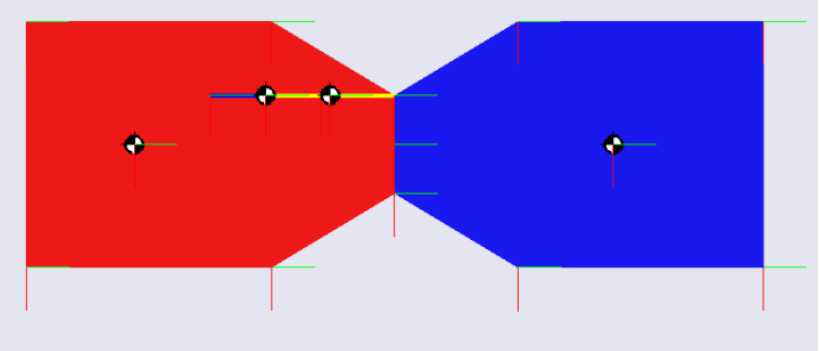

Figure 10: MATLAB Simulink SimMechanics ${ }^{T M}$ Model

\section{System Model}

Inducing an articulation angle requires a steering torque to be exerted about the articulation joint. This requires coupling the hydraulics and mechanics models. For the Adams model to accept steering force as an input, the 
steering actuator was modeled as a linear spring / damper element connected to both subframes (fig. 11).

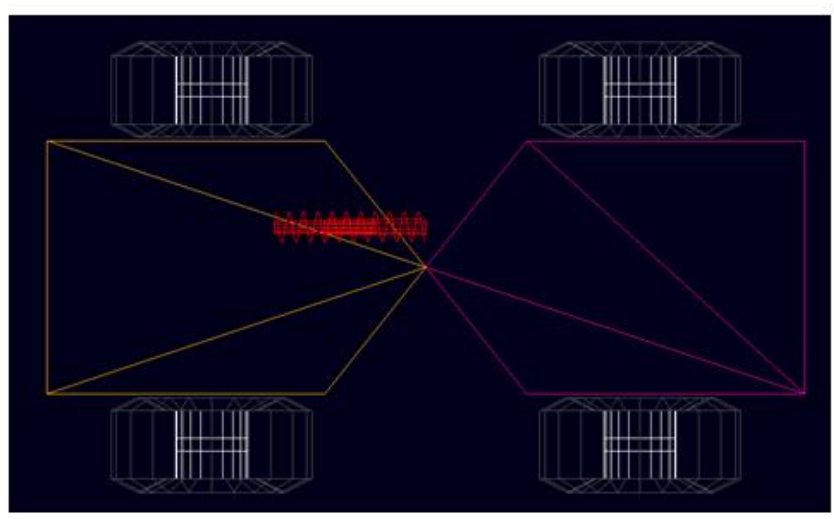

Figure 11: Adams Model Linear Actuator Setup

The Adams plant model was then exported to Simulink in a manner that inputs actuator force and outputs the articulation angle and rate as shown in fig. 12.

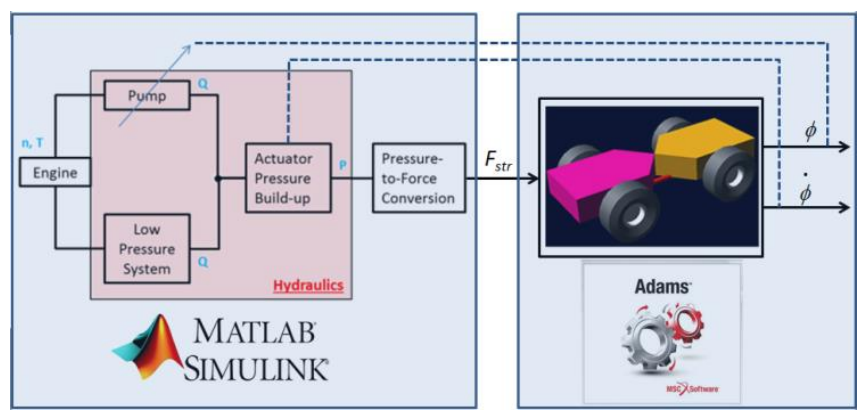

Figure 12: Exported Adams Plant Model into Simulink®

\section{Simulation Results}

Two maneuvers were simulated: a static maneuver where the vehicle speed is set to zero and the articulation angle is varied between $+25^{\circ}$ and $-25^{\circ}$ emulating a static loading cycle; second, a dynamic maneuver where the vehicle forward speed is set to $20 \mathrm{~km} / \mathrm{hr}$ and the vehicle direction changes between $\pm 9^{\circ}$ mimicking a lane change maneuver. The maneuvers were realized via a simple proportional controller providing closed-loop position control. The relevant parameters used during the simulation are given in tab. 2.

\begin{tabular}{|l|l|l|}
\hline Description & Value & Unit \\
\hline Pump Displacement Volume & 18 & $\mathrm{~cm}^{3} / \mathrm{rev}$ \\
\hline Engine/Pump Speed & 1500 & $\mathrm{rev} / \mathrm{min}$ \\
\hline Actuator Piston Diameter & 0.078 & $\mathrm{~m}$ \\
\hline Actuator Rod Diameter & 0.032 & $\mathrm{~m}$ \\
\hline Fluid Bulk Modulus & $1.9 \mathrm{e} 9$ & $\mathrm{~N} / \mathrm{m}^{2}$ \\
\hline Fluid Density & 870 & $\mathrm{Kg} / \mathrm{m}^{3}$ \\
\hline
\end{tabular}

\begin{tabular}{|l|l|l|}
\hline Low Pressure System Pressure & 25 & Bar \\
\hline Articulation Joint Damping & 350 & N.m.s/rad \\
\hline
\end{tabular}

Table 2: Simulation Parameters

\subsection{Static Maneuver}

Figure 13 shows the vehicle articulation angle varying between $+25^{\circ}$ and $-25^{\circ}$. The ramp-up and ramp-down rates confirm the sizing of the DC steering pump, which was sized to meet the same cycle requirements as the baseline hydrostatic steering system.

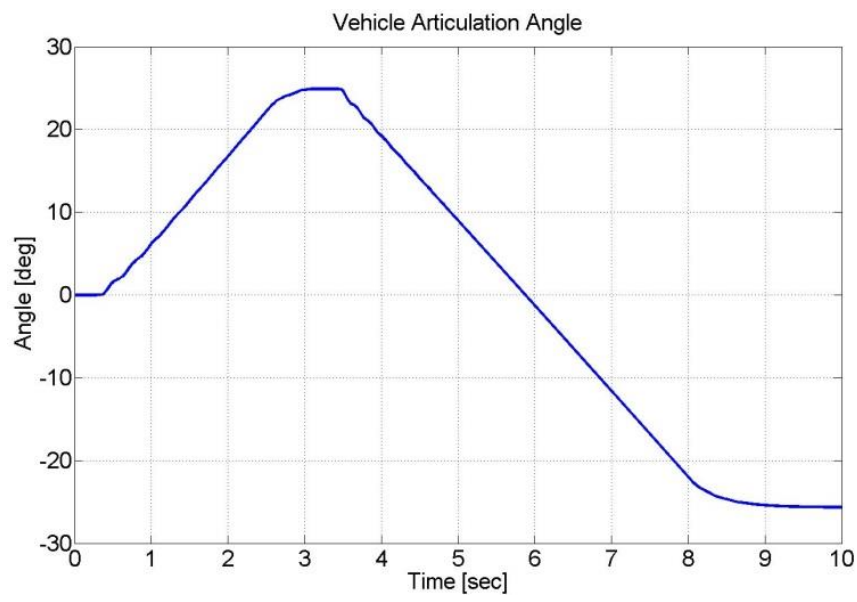

Figure 13: Static Maneuver-Articulation Angle

Figure 14 shows the pressure rise inside the corresponding chambers of the steering actuator. The results serve multiple validation checks. First, given that the steering actuator is mounted with its piston side (A) towards the rear of the vehicle, articulating the vehicle to the left (positive angle) requires the pressure on the rod side (B) to rise and vice versa. Second, the model accurately predicts that higher pressure is needed to articulate the vehicle left than right, since side B has a smaller area than side A. Lastly, the low pressure system successfully kept the low pressure side at the specified setting of $25 \mathrm{bar}$, which confirms the sizing as well as validates the intricate modeling of the low pressure system.

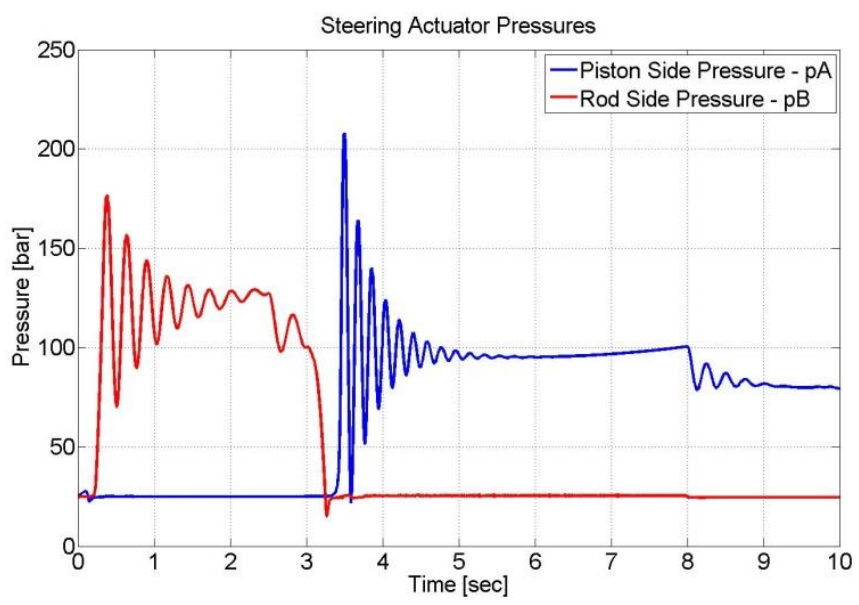

Figure 14: Static Maneuver-Actuator Pressure 
Figure 15 shows the net steering actuator force resulting from the pressure differential across the actuator sides.

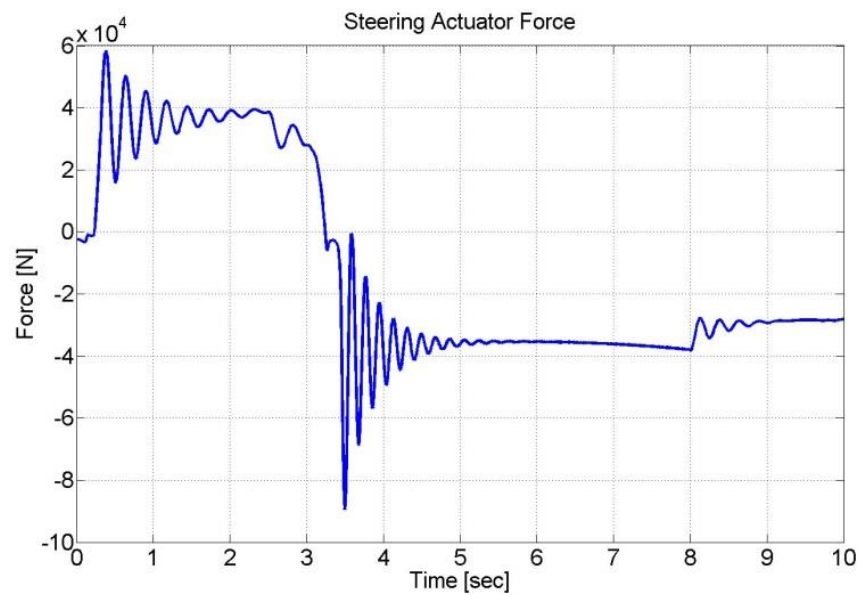

Figure 15: Static Maneuver-Steering Actuator Force

\subsection{Dynamic Maneuver}

Figure 16 shows the articulation angle of the vehicle during the dynamic maneuver. The vehicle executed a lane change maneuver by changing direction in both ways while driving at $20 \mathrm{~km} / \mathrm{hr}$.



Figure 16: Dynamic Maneuver - Articulation Angle

Figure 17 shows the pressures inside the actuator chambers as the vehicle articulates. Similar results were obtained as in the static maneuver. Articulating the vehicle to the left (positive) requires the pressure on the rod side (B) to rise and vice versa, higher pressure levels are needed to articulate the vehicle left than right since side $\mathrm{B}$ has a smaller area than side A, and the low pressure system kept the low pressure side at the specified setting of $25 \mathrm{bar}$.

Figure 18 shows the corresponding steering actuator force resulting from the pressure differential across the actuator chambers. Smaller force magnitudes are observed since the friction coefficient between the tire and ground is lower in dynamic conditions than static ones. When the vehicle reaches the commanded position, the force magnitude returns to zero since no further steering effort is required.

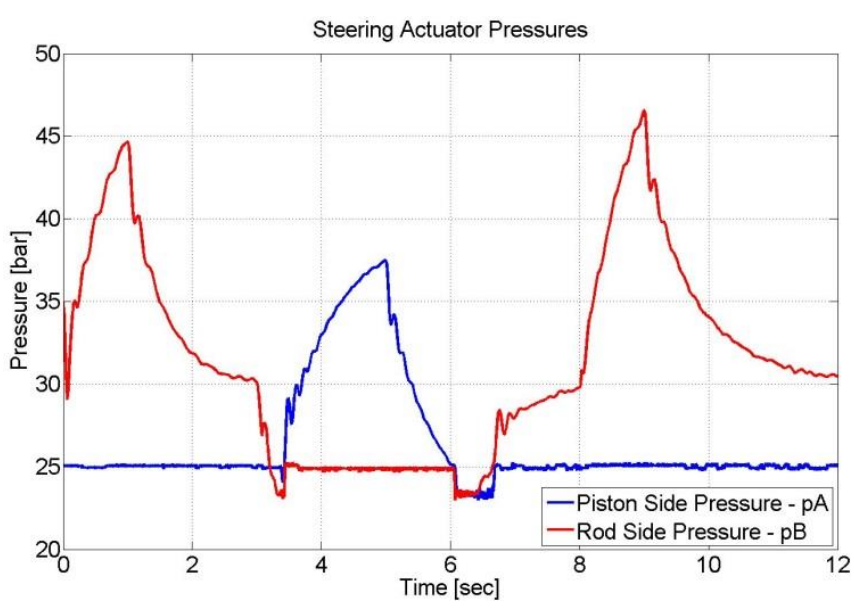

Figure 17: Dynamic Maneuver - Actuator Pressures

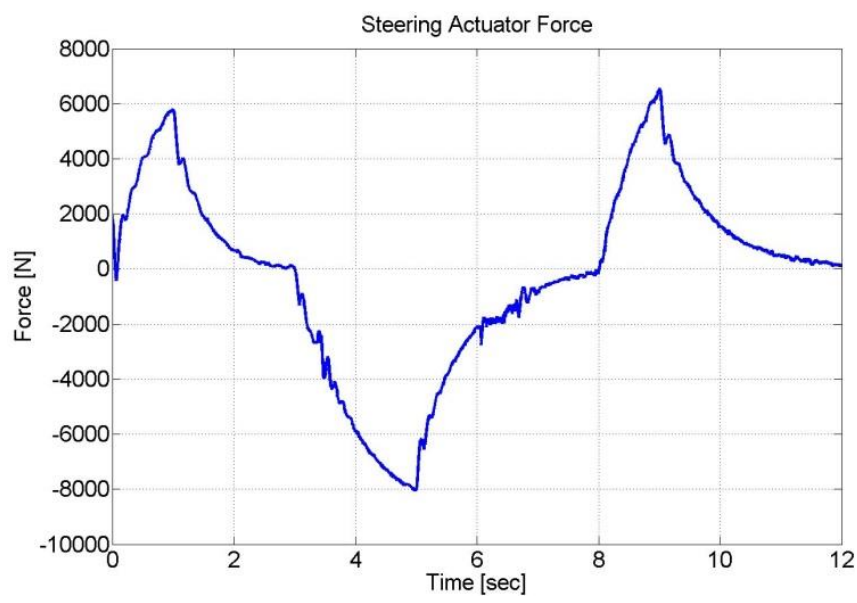

Figure 18: Dynamic Maneuver - Actuator Force

Figure 19 shows the tire lateral slip angles as the vehicle direction deviates from straight-line forward motion. The sign and magnitude of both axles accurately reflect the maneuver at hand, which were verified against manually performed calculations based on eq. (34) and eq. (35). The fact that the slip angles of the tires on the same axle almost overlap, which allows for modeling the vehicle as a bicycle and combining both tires into one.

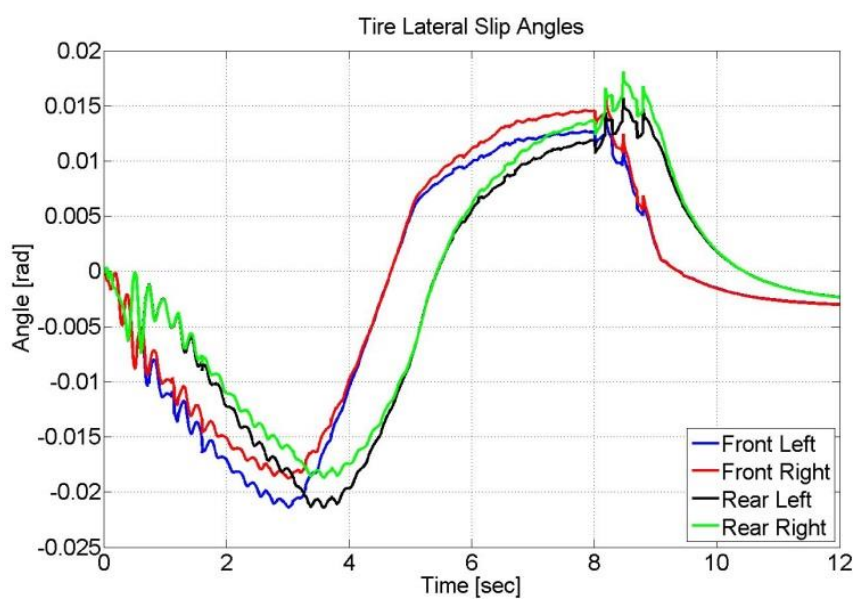

Figure 19: Dynamic Maneuver - Tire Lateral Slip Angles 
Figure 20 shows the tire lateral forces resulting from the slip angles shown in fig. 19, the tire normal loads, and the surface type. The sign and magnitude of the tire forces match the theoretical values as computed from eq. (36) and eq. (37).

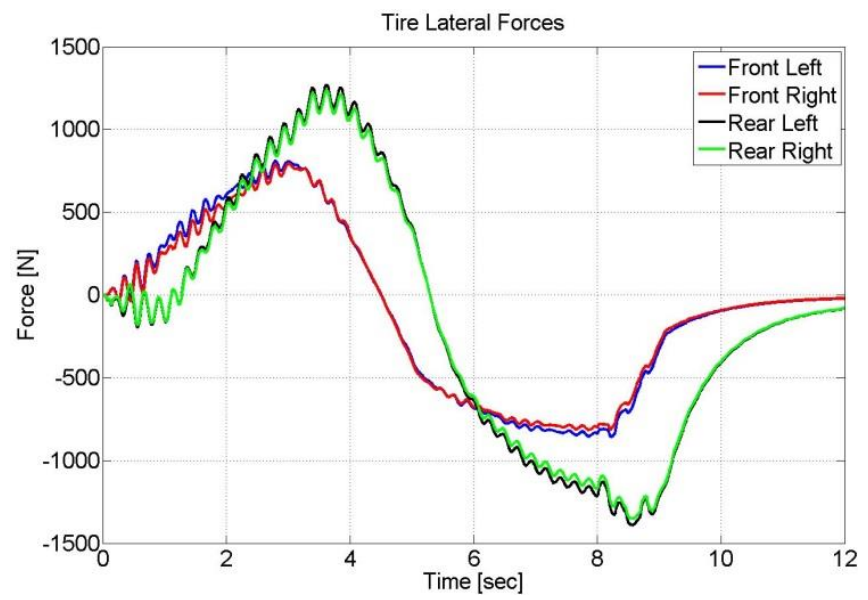

Figure 20: Dynamic Maneuver - Tire Lateral Forces

\section{Future Work}

The results obtained in this paper will be used to aid in both the derivation process as well as the validation process of linearized models for the hydraulic subsystem, the dynamic subsystem, and the entire system. Linear models allow for exploiting modern control theory techniques pertaining to linear time-invariant (LTI) systems. After designing a controller, the generated control algorithms and dynamic models will be validated and fine-tuned based on measurement results obtained from a baseline test vehicle. This requires retrofitting the test vehicle with a renovated steering column assembly, tactile feedback device, a DC axial piston pump, sensors, actuators, electronics, and a realtime controller.

\section{Conclusion}

A novel electro-hydraulic steer-by-wire system realized via DC technology has been proposed. High fidelity nonlinear dynamic models of the two subsystems that are at the heart of the new system, hydraulics and mechanics, were developed and validated. Finally, a sophisticated nonlinear system plant model is now available on hand, which will be used for validating the linearized models under investigation, paving the road in front of the design and development of a robust steer-by-wire system controller.

The technology will be demonstrated on a compact wheel loader. Baseline measurements of the stock loader have been conducted, and will be used to compare against the new measurement results after the implementation of the new steering system.

\section{Nomenclature}

\begin{tabular}{|l|l|}
\hline$Q_{e}$ & Pump Effective Flow Rate \\
\hline$\beta$ & Pump Swash Plate Angle (Normalized) \\
\hline
\end{tabular}

\begin{tabular}{|c|c|}
\hline$V_{d}$ & Pump Displacement Volume (Derived) \\
\hline$n$ & Pump Speed \\
\hline$Q_{s}$ & Pump/Motor Volumetric Loss \\
\hline$T_{e}$ & Pump/Motor Effective Torque \\
\hline$T_{s}$ & Pump/Motor Torque Loss \\
\hline$\Delta p$ & Pressure Differential Across Pump/Motor Ports \\
\hline$K_{Q}$ & Pump/Motor Volumetric Loss Coefficient \\
\hline$K_{T}$ & Pump/Motor Torque Loss Coefficient \\
\hline$p$ & Pressure \\
\hline$Q$ & Flow Rate \\
\hline$C_{H}$ & Hydraulic Capacitance \\
\hline$\dot{x}$ & Actuator Velocity \\
\hline$A$ & Area \\
\hline$V$ & Volume \\
\hline$\alpha$ & Actuator Area Ratio \\
\hline$K_{L i}$ & Coefficient of Internal Leakage of Actuator \\
\hline$K$ & Fluid Bulk Modulus \\
\hline$H$ & Maximum Actuator Stroke (End-to-End) \\
\hline$x$ & Actuator Position \\
\hline$V_{\text {dead }}$ & Actuator Dead Volume \\
\hline$\mu$ & Fluid Dynamic Viscosity \\
\hline$v$ & Fluid Kinematic Viscosity \\
\hline$\rho$ & Fluid Density \\
\hline$\overline{F_{R}}$ & Resultant Friction Force \\
\hline$F_{C}$ & Coulomb Friction Force \\
\hline$F_{H}$ & Static Friction Force \\
\hline$\tau_{H}$ & Static Friction Force Constant \\
\hline$l_{L}$ & Transmission Line Length \\
\hline$R_{L}$ & Transmission Line Radius \\
\hline$y_{c}$ & Pilot-Operated Check Valve Spool Displacement \\
\hline$Q_{c}$ & Pilot-Operated Check Valve Flow Rate \\
\hline$\alpha_{D}$ & $\begin{array}{l}\text { Pilot-Operated Check Valve Discharge } \\
\text { Coefficient }\end{array}$ \\
\hline$d_{c}$ & Pilot-Operated Check Valve Cone Diameter \\
\hline$y_{c}$ & Pilot-Operated Check Valve Cone Position \\
\hline$\overline{A_{c}}$ & Pilot-Operated Check Valve Cone Orifice Area \\
\hline
\end{tabular}




\begin{tabular}{|c|c|}
\hline$p_{L P}$ & Pressurized Low Pressure \\
\hline$p_{1}$ & Pilot-Operated Check Valve Pilot Pressure \\
\hline$p_{2}$ & $\begin{array}{l}\text { Pilot-Operated Check Valve Cylinder / Outlet } \\
\text { Pressure }\end{array}$ \\
\hline$F_{K 0}$ & $\begin{array}{l}\text { Pilot-Operated Check Valve Spring Pre-load } \\
\text { Force }\end{array}$ \\
\hline$K_{0}$ & Pilot-Operated Check Valve Spring Rate \\
\hline$A_{s p}$ & Pilot-Operated Check Valve Spool Area \\
\hline$\omega_{S V}$ & Servovalve Natural Frequency \\
\hline$\zeta_{S V}$ & Servovalve Damping Ratio \\
\hline$F_{\text {str }}$ & Steering Actuator Force \\
\hline$r_{j}$ & $\begin{array}{l}\text { Normal Distance Between the Articulation Joint } \\
\text { and the Steering Actuator Force Line of Action }\end{array}$ \\
\hline$C_{a j}$ & Articulated Joint Torsional Damping Coefficient \\
\hline$N_{f}$ & Front Axle Normal Load \\
\hline$\mu_{t f}$ & Friction Coefficient Between the Tire and Ground \\
\hline$w b$ & Vehicle Wheelbase \\
\hline$d_{a j}$ & Articulation Joint Damping Coefficient \\
\hline $\mathrm{d}_{\text {Tire_Lat }}$ & Tires Lateral Damping Coefficient \\
\hline$\omega_{\mathrm{f}}$ & Front Sub-frame Articulation Angle Rate \\
\hline$L$ & Lagrangian Function \\
\hline$T$ & Kinetic Energy \\
\hline$V$ & Potential Energy \\
\hline$D$ & Dissipative Function \\
\hline$Q_{i}$ & Generalized Forces \\
\hline$m_{f}$ & Front Sub-frame Mass \\
\hline$m_{r}$ & Rear Sub-frame Mass \\
\hline$X_{f}$ & Front Sub-frame Global Abscissa \\
\hline$Y_{f}$ & Front Sub-frame Global Ordinate \\
\hline$x_{f}$ & Front Sub-frame Local Abscissa \\
\hline$y_{f}$ & Front Sub-frame Local Ordinate \\
\hline$I_{f}$ & Front Sub-frame Moment of Inertia \\
\hline$I_{r}$ & Rear Sub-frame Moment of Inertia \\
\hline$\psi$ & Front Sub-frame Yaw Angle \\
\hline$\theta$ & Rear Sub-frame Yaw Angle \\
\hline$\phi$ & Articulation Angle \\
\hline$a$ & Distance between Front C.G. and Front Axle \\
\hline$b$ & $\begin{array}{l}\text { Distance between Front C.G. and Articulation } \\
\text { Joint }\end{array}$ \\
\hline$c$ & Distance between Rear C.G. and Articulation \\
\hline
\end{tabular}

\begin{tabular}{|c|c|}
\hline & Joint \\
\hline$d$ & Distance between Rear C.G. and Rear Axle \\
\hline$K_{a j}$ & Articulation Joint Equivalent Torsional Stiffness \\
\hline$C_{a j}$ & Articulation Joint Equivalent Torsional Damping \\
\hline$u_{f}$ & Front Sub-frame Longitudinal Velocity \\
\hline$v_{f}$ & Front Sub-frame Lateral Velocity \\
\hline Fy & Tire Lateral Force \\
\hline$M_{Z}$ & Tire Aligning Moment \\
\hline$\alpha_{s}$ & Tire Slip Angle \\
\hline$\alpha_{f}$ & Front Tires Slip Angle \\
\hline$\alpha_{r}$ & Rear Tires Slip Angle \\
\hline$N$ & Axle Normal Load \\
\hline$C_{\alpha}$ & Tires Lateral Force Coefficient \\
\hline$C_{M \alpha}$ & Tires Aligning Moment Coefficient \\
\hline$g$ & Gravity Constant \\
\hline$\gamma$ & $\begin{array}{l}\text { Conversion Factor Between Actuator Linear } \\
\text { Motion and Vehicle Articulation Motion }\end{array}$ \\
\hline$C_{d}$ & Actuator Viscous Damping Coefficient \\
\hline$m_{r}$ & Actuator Rod Mass \\
\hline$F_{L}$ & Actuator Load Force \\
\hline$D C$ & Displacement Control \\
\hline$P O C V$ & Pilot-Operated Check Valve \\
\hline$D O F$ & Degree(s) of Freedom \\
\hline$C G$ & Center of Gravity \\
\hline$E O M$ & Equation(s) of Motion \\
\hline
\end{tabular}

\section{References}

[1] Azad, N. Dynamic Modelling and Stability Controller Development for Articulated Steer Vehicles. Ph.D. dissertation, University of Waterloo. Waterloo, Ontario, Canada. 2006.

[2] Chen, C. and Tomizuka, M. Modeling and Control of Articulated Vehicles. Report number UCB-ITS-PRR-9742, California Partners for Advanced Transit and Highways, Institute of Transportation Studies, Berkeley, California. 1997.

[3] Crolla D. Automotive Engineering: Powertrain, Chassis System and Vehicle Body. Elsevier Science \& Technology Books. Burlington, MA. 2009.

[4] Daher, N. and Ivantysynova, M. Electro-hydraulic energy-saving power steering systems of the future. 
Proceedings of the $7^{\text {th }}$ FPNI PhD Symposium, Reggio Emilia, Italy, pp. 929 - 952. 2012.

[5] Greenwood, D. Principles of Dynamics. Prentice-Hall, Inc., Englewood Cliffs, New Jersey. 1988.

[6] Horton D.N.L. and Crolla D.A. Theoretical analysis of the steering behaviour of articulated frame steer vehicles. Vehicle System Dynamics, vol. 15, pp. 211234. 1986.

[7] Merritt, H.E. Hydraulic Control Systems. John Wileys and Sons, Cincinnati, Ohio. 1967

[8] Milliken, W.F. and Milliken, D.L. Race Car Vehicle Dynamics. SAE International. 1995.

[9] Rahmfeld, R. Development and Control of Energy Saving Hydraulic Servo Drives for Mobile Systems. Ph.D. Thesis. Dept. of Aircraft Systems, Technical University of Hamburg-Harburg. Hamburg, Germany. 2002.

[10] Rahmfeld, R. and Ivantysynova, M. Energy Saving Hydraulic Actuators for Mobile Machines. Proceedings of 1st Bratislavian Fluid Power Sysmposium, pp. 47-57. Častá - Píla, Slovakia. 1998

[11] Rahmfeld, R. and Ivantysynova, M. Displacement Controlled Wheel Loader - a simple and clever Solution. $4^{\text {th }}$ International Fluid Power Conference Proceedings, pp. 183-196. Dresden, Germany. 2004.

[12] Williamson, C., Zimmerman, J., and Ivantysynova, M. Efficiency Study of an Excavator Hydraulic System Based on Displacement-Controlled Actuators. ASME/Bath Workshop on Fluid Power and Motion Control (FPMC08). Bath, UK. 2008.

[13] Williamson, C and Ivantysynova, M. Power Optimization for Multi-Actuator Pump-Controlled Systems. Proceedings of the 7th International Fluid Power Conference Aachen 2010 (7IFK), Vol 1. pp.91 102. 2010.

[14] Wittren, R.A. Power Steering For Agricultural Tractors. American Society of Agricultural Engineers, Winter Meeting Distinguished Lecture Series. Chicago, IL, USA. 1975. 